\title{
Penguatan Ekosistem Pesisir: Monitoring dan Pembelajaran Pembangunan Alat Pemecah Ombak (AP0) di Kota Semarang
}

\author{
Reny Yesiana ${ }^{1}$ \\ Departemen Perencanaan Wilayah dan Kota \\ Universitas Diponegoro, Semarang, Indonesia
}

\section{Itsna Yuni Hidayati}

Initiative for Regional Development and Environmental Management (IRDEM)

Semarang, Indonesia

\section{Gunawan Wicaksono}

Badan Lingkungan Hidup (BLH) Kota Semarang

Semarang, Indonesia

Artikel Masuk : 7 November 2016

Artikel Diterima : 6 Desember 2016

Tersedia Online : 30 Desember 2016

\begin{abstract}
Abstrak: Perubahan iklim menjadi salah satu penyebab kerusakan lingkungan dan perlu diantisipasi. Di Indonesia, termasuk di Kota Semarang, dampak yang ditimbulkan akibat perubahan iklim juga terjadi. Kerusakan tambak dan hutan mangrove akibat abrasi dan kenaikan muka air laut secara terus menerus menjadi contoh dampak yang terjadi di Kota Semarang. Dampak perubahan iklim yang siginifikan diperparah dengan rendahnya pengetahuan masyarakat terkait ancaman perubahan iklim. Hal ini akhirnya berpengaruh terhadap pendapatan petani dari hasil tambak yang terus menerus menurun. Fakta tersebut melatarbelakangi Mercy Corps Indonesia bekerja sama dengan pemerintah Kota Semarang dan Yayasan Bintari mengembangkan kegiatan yang bertujuan memperkuat perlindungan wilayah pesisir melalui pembangunan Alat Pemecah Ombak (APO) dalam Program "Peningkatan Ketahanan Masyarakat Pesisir Melaui Penguatan Ekosistem Mangrove dan Pengembangan Mata Pencaharian Berkelanjutan di Kota Semarang”. Pembangunan alat pemecah ombak dalam bentuk APO ban dan bambu yang dikenal dengan istilah Hybrid Engineering (HE) selesai dilaksanakan pada tahun 2016. Tujuan dari penulisan artikel ini adalah sebagai kajian monitoring pelaksanaan dan pembelajaran pembangunan APO terhadap masyarakat di kawasan pesisir Kota Semarang khususnya di Kecamatan Genuk dan Tugu. Pendekatan yang digunakan adalah pendekatan campuran (mix method) kuantitatif dan kualitatif dengan metode penelitian deskriptif sehingga kajian lebih menekankan pada analisis fakta-fakta terukur yang digambarkan dalam bentuk deskripsi yang didukung oleh informasi yang digali dari masyarakat melalui wawancara dan arsip-arsip pada laporan-laporan yang telah disusun sebelumnya yang memuat perkembangan pembangunan APO. Berdasarkan hasil penelitian yang dilakukan, pembangunan APO banyak memberikan dampak positif,
\end{abstract}

\footnotetext{
Korespondensi Penulis: Departemen Perencanaan Wilayah dan Kota, Universitas Diponegoro, Semarang, Indonesia Email: renyyesiana@gmail.com
} 
sehingga masyarakat secara sadar melakukan perawatan secara mandiri agar dampak positif yang mereka terima dapat dirasakan dalam jangka waktu yang lama.

Kata Kunci: APO, ekosistem, monitoring, penguatan, pesisir

\begin{abstract}
Climate change has been one of the major causes of environmental damage which needs to be anticipated early. In Indonesia, particularly in Semarang City, it has destroyed ponds and mangrove forests through erosion and sea level rise processes. The significant impact of climate change is exacerbated by the lack of public knowledge related to its threat, which in turn affects to the decrease in farmers' income. This situation encouraged the Mercy Corps Indonesia in cooperation with the Government of Semarang Municipality and the Bintari Foundation to develop activities for strengthening the coastal area protection through the development of seawalls under the program named "Enhancing Coastal Community Resilience by Strengthening Mangrove Ecosystem Services and Developing Sustainable Livelihood in Semarang City". The construction of tires seawalls and Hybrid Engineering (HE) were completed in 2016. It had immediate impacts on the community in coastal areas. This article aims to review the monitoring of and the lesson learned from the seawalls construction for the communities in coastal areas, particularly in Genuk and Tugu Sub-districts. The methods used were mixed method research with a descriptive approach focusing on the analysis of measurable descriptive facts, which was supported by interviews for collecting tacit information in the community and reviews of archived reports on its development progress. The results showed that the seawalls development provides many positive effects for the community so that they are willing to maintain it for their own sake in the long term.
\end{abstract}

Keywords: seawall, ecosystem, monitoring, strengthening, coastal area

\title{
Pendahuluan
}

Kerusakan lingkungan laut dan pesisir salah satunya disebabkan oleh naiknya permukaan air laut yang dipicu oleh perubahan iklim. Susandi, Herlianti, Tamamadin, dan Nurlela (2008) menyebutkan dengan adanya kenaikan muka air laut menyebabkan tergenangnya air di wilayah daratan dekat pantai. Kenaikan muka air laut selain mengakibatkan perubahan arus laut pada wilayah pesisir juga mengakibatkan rusaknya ekosistem mangrove (Suhelmi \& Prihatno, 2014). Apabila keberadaan mangrove tidak dapat dipertahankan lagi, maka abrasi pantai akan kerap terjadi karena tidak memiliki penahan gelombang. Pencemaran dari sungai ke laut akan meningkat karena tidak adanya filter polutan dan zona budidaya akuakultur akan terancam dengan sendirinya (Kimpraswil dalam Kusmana, 2010).

Kota Semarang merupakan salah satu daerah pesisir di Provinsi Jawa Tengah yang juga terkena dampak dari kenaikan paras air laut atau rob. Hal ini mengingat adanya beberapa wilayah yang langsung berhadapan dengan perairan, berada pada dataran rendah serta kurangnya lapisan mangrove sebagai pelindung pantai yang alami. Berdasarkan data dari Dinas Kelautan dan Perikanan tahun 2011, Kota Semarang memiliki panjang garis pantai sesuai dengan lekuk daratan sepanjang $36,63 \mathrm{~km}$ dengan luas daratan pesisir adalah $9.111,28$ ha dan luas perairan sesuai kewenangan seluas $10.048,80$ ha. Wilayah Kota Semarang memiliki luas wilayah $373,70 \mathrm{~km}^{2}$. Secara administratif, Kota Semarang terbagi menjadi 16 Kecamatan dan 4 diantaranya berbatasan dengan laut yaitu Kecamatan Tugu seluas 2.985,99 ha atau 31,78\% dari luas Kota Semarang, Semarang Barat seluas 2.247,97 ha $(21,74 \%)$, Semarang Utara seluas $1.168,94$ ha $(10,97 \%)$ dan Kecamatan Genuk seluas $2.708,38$ ha $(27,39 \%)$ (BPS Kota Semarang, 2010). 
Berdasarkan fakta tersebut, Mercy Corps Indonesia, Pemerintah Kota Semarang, Yayasan Bintari, dan akademisi yang didanai Rockefeller Foundation mengimplementasikan program "Peningkatan Ketahanan Masyarakat Pesisir Melalui Penguatan Ekosistem Mangrove dan Pengembangan Mata Pencaharian Berkelanjutan di Kota Semarang”. Program ini telah diimplementasikan sejak tahun 2013 di Pesisir Kota Semarang, yaitu di wilayah Kecamatan Tugu dan Kecamatan Genuk. Tujuan program tersebut adalah meningkatkan ketahanan di sepanjang wilayah pesisir Kota Semarang dalam beradaptasi dengan perubahan iklim.

Untuk mencapai tujuan tersebut, salah satu sasaran yang harus dicapai adalah meningkatkan pelayanan ekosistem dan memperkuat perlindungan wilayah pesisir Kecamatan Tugu dan Kecamatan Genuk selama tahun 2013-2016. Indikator yang harus dicapai dalam sasaran ini adalah pembangunan 800 meter alat pemecah ombak tambahan di wilayah pesisir Kecamatan Tugu dan Genuk pada tahun 2016. Pada tahun 2016, pembangunan alat pemecah ombak baik di Kecamatan Tugu maupun Kecamatan Genuk telah selesai dilakukan.

Pembangunan APO merupakan salah satu konsep perlindungan pesisir yang berbentuk rekayasa stuktur (hard engineering) (Reeve dalam Al Hakim, 2015). APO merupakan bangunan yang digunakan untuk melindungi daerah perairan dari gangguan gelombang. Selain untuk melindungi bibit mangrove, APO juga diharapkan dapat mengurangi laju erosi pantai dan menangkap sedimen di daerah yang dilindungi (Yulistiyanto, 2009). Menurut Triatmodjo (1999), untuk pesisir Kota semarang dengan tipe sedimen lumpur pasiran yang mempunyai daya dukung rendah, terdapat beberapa tipe APO, yaitu tembok laut (seawall), revetment, groin, alat pemecah ombak (APO). Sedangkan tipe-tipe alat pemecah ombak (APO) menurut Yulistiyanto (2009) serta Wiharja dan Naviarta (2015), yaitu APO tipe box-beton (kubus beton), APO tipe kayu berbentuk lengkung, APO tipe kayu berbentuk lurus, APO tipe paralon dan ban, APO tipe buis beton, APO tipe bambu ban dan APO tipe brushwood dam/tipe permeable dam/tipe hybrid engineering.

Kajian APO di pesisir Kota Semarang (Kecamatan Tugu dan Genuk) telah dilakukan sebelumnya oleh Hartati, Pribadi, Astuti, Yesiana, dan Yuni pada tahun 2016 dengan judul "Kajian Pengamanan dan Perlindungan Pantai di Wilayah Pesisir Kecamatan Tugu dan Genuk, Kota Semarang”. Hasil kajian tersebut adalah kesesuaian tipe bangunan APO untuk wilayah pesisir Tugu dan Genuk. APO tipe bambu ban dapat diaplikasikan dan dibangun di Kelurahan Tugurejo (Kecamatan Tugu) dan APO tipe hybrid engineering (HE) dapat dibangun pada pesisir Trimulyo (Kecamatan Genuk). Pemilihan APO bambu ban berdasarkan pada pertimbangan dasar pantai yang berupa lumpur berpasir. APO tipe bambu ban mampu melindungi tambak dari gelombang dan pasang tinggi, sedangkan pertimbangan penggunaan HE di Trimulyo didasarkan pada sedimen lumpur halus. HE bertujuan untuk memulihkan pantai lumpur untuk daerah penanaman mangrove juga untuk mengembalikan wilayah yang hilang karena erosi dan abrasi. Pembangunan APO tipe ini memungkinkan pemulihan habitat untuk mangrove yang membutuhkan pendangkalan sedimen halus dan tingkat sedimentasi yang lebih besar sehingga pemulihan kerusakan pesisir dapat dilakukan lebih cepat (Hartati et al., 2016).

Hasil dari kajian tersebut diimplementasikan oleh Mercy Corp Indonesia untuk melindungi pesisir Kecamatan Tugu dan Genuk sepanjang 800 meter. Angka ini diperoleh dari kebutuhan masyarakat melalui Focus Group Discussion (FGD). Selama proses pembangunan APO berlangsung, selalu disertai dengan monitoring yang bertujuan untuk memantau dan mengambil pembelajaran dari kegiatan tersebut. Monitoring bisa diartikan sebagai evaluasi terhadap implementasi kebijakan (Dunn, 2002). Rifai (1986) menjelaskan bahwa fungsi monitoring sebagai pengukur kemajuan, alat perencanaan dan alat 
perbaikan. Monitoring juga memiliki peranan penting seperti halnya analisis dan observasi, karena dengan ketiga hal tersebut data menjadi lebih berguna (Huang \& Liu, 2009).

Dengan demikian, tulisan ini bertujuan untuk mengkaji monitoring dan pembelajaran dari pembangunan Alat Pemecah Ombak (APO) yang dibangun masyarakat di kawasan pesisir. Hasil pembelajaran tersebut diharapkan dapat memberikan manfaat kepada pemerintah daerah, $\mathrm{NgO}$ dan akademisi dalam mengawal pembangunan APO di daerah masing-masing.

Pembahasan dalam penelitian ini meliputi pendahuluan, lingkup wilayah dan metode, hasil dan pembahasan, serta kesimpulan. Pendahuluan berisi mengenai latar belakang dan masalah yang mendasari pengembangan program dan tujuan disusunnya kajian. Lingkup wilayah dan metode membahas mengenai lokasi penelitian, metode analisis yang digunakan dan responden penelitian. Bagian hasil dan pembahasan mendiskusikan monitoring pelaksanaan pembangunan alat pemecah ombak yang telah diimplementasikan oleh Mercy Corps Indonesia dan pembelajaran (lesson learned) yang diperoleh dari kegiatan dan bagian terakhir adalah kesimpulan.

\section{Lingkup Wilayah dan Metode Penelitian}

Program "Peningkatan Ketahanan Masyarakat Pesisir Melaui Penguatan Ekosistem Mangrove dan Pengembangan Mata Pencaharian Berkelanjutan di Kota Semarang" diterapkan disebagian besar wilayah Kecamatan Tugu, yakni di Kelurahan Mangkang Kulon, Mangunharjo, Mangkang Wetan, Karanganyar, dan Tugurejo serta Kelurahan Trimulyo di Kecamatan Genuk melalui beberapa kegiatan yang berbeda-beda. Pembangunan Alat Pemecah Ombak (APO) dalam program ini dilakukan di Kelurahan Trimulyo Kecamatan Genuk dan Kelurahan Karanganyar dan Tugurejo Kecamatan Tugu. Sehingga kajian ini merupakan hasil monitoring pelaksanaan pembangunan APO yang dibangun oleh Mercy Corps Indonesia yang bekerja sama dengan Pemerintah Kota Semarang, Bintari, dan akademisi yang didanai oleh Rockefeller Foundation.

Pendekatan yang digunakan dalam kajian ini adalah pendekatan campuran (mix method) kuantitatif dan kualitatif dengan metode penelitian deskriptif sehingga kajian lebih menekankan pada analisis fakta-fakta terukur yang digambarkan dalam bentuk deskripsi dan deskripsi didukung dengan informasi yang digali pada masyarakat melalui wawancara dan penggalian informasi dari arsip-arsip pada laporan-laporan yang telah disusun sebelumnya yang memuat perkembangan pembangunan APO. Teknik pengumpulan data yang digunakan adalah survei primer melalui wawancara mendalam dengan responden dan survei sekunder melalui pengumpulan arsip-arsip dokumen. Responden dalam penelitian ini adalah petani tambak dan masyarakat yang tambaknya dijadikan lokasi untuk membangun APO sehingga total responden dalam penelitian berjumlah 6 orang. Tabel 1 menunjukkan nama-nama responden dalam kajian ini. Lokasi kajian dilakukan sesuai dengan wilayah pembangunan APO adalah Kelurahan Karanganyar, Kelurahan Tugurejo dan Kelurahan Trimulyo. Gambar 1 menunjukkan peta lokasi kajian sekaligus lokasi pembangungan APO yang dilakukan. 
Tabel 1. Nama Responden dalam Pembangunan APO

\begin{tabular}{c|l|l}
\hline No & \multicolumn{1}{|c|}{ Nama } & \multicolumn{1}{c}{ Kelompok } \\
\hline 1 & Muhyi & Kelompok Tani Tambak Sido Rukun \\
\hline 2 & Kaswan & - \\
\hline 3 & Sugeng & Kelompok Tani Tambak Sido Rukun \\
\hline 4 & Juri & Kelompok Tani Tambak Sido Rukun \\
\hline 5 & Sumadi & Sringin \\
\hline 6 & Yudi & Sringin \\
\multicolumn{2}{l}{ Sumber: Penyusun, 2016 }
\end{tabular}

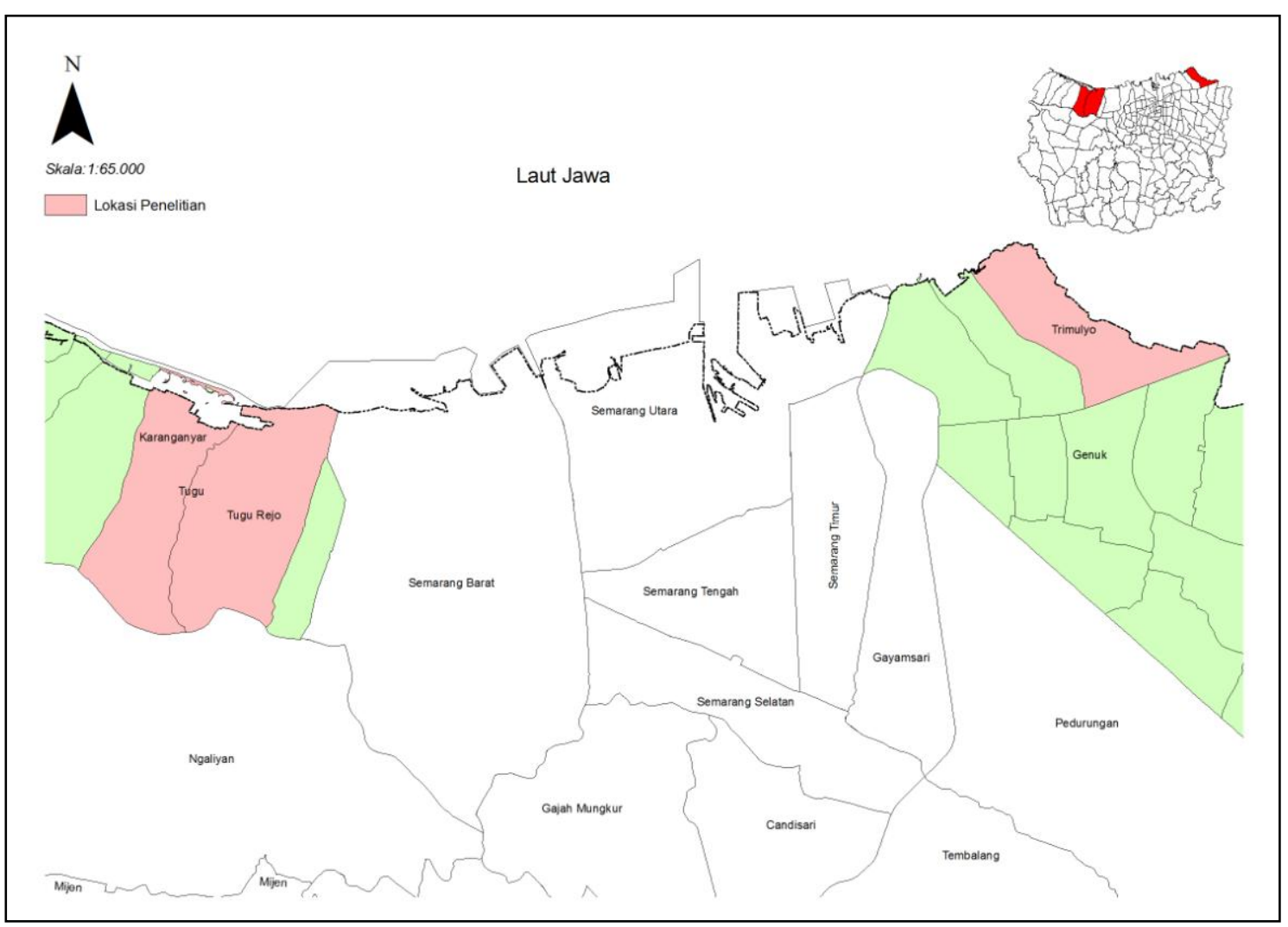

Sumber: Bappeda Kota Semarang, 2011

Gambar 1. Lokasi Penelitian dan Lokasi Pembangunan APO

\section{Gambaran Umum Alat Pemecah Ombak yang Dikembangkan Mercy Corps Indonesia}

Pemecah gelombang atau pemecah ombak yang dalam Bahasa Inggris dikenal dengan seawalls adalah prasarana yang dibangun untuk memecahkan ombak atau gelombang dengan menyerap sebagian energi gelombang. Pemecah gelombang digunakan untuk mengendalikan abrasi (Wahyudi, 2016). Pada program yang dikembangkan oleh Mercy Corps Indonesia di Kota Semarang terdapat dua jenis pemecah ombak yang dibangun, yakni APO ban bekas dan APO dari bambu atau Hybrid Engineering (HE) ${ }^{2}$.

\footnotetext{
${ }^{2}$ Hybrid Engineering (HE) adalah bangunan pantai dengan struktur permeable (Astra, Etwin, Arief, \& Maulana, 2014). Konstruksi ini dimaksudkan untuk menangkap sedimen yang dibawa oleh arus laut. Konstruksi ini
} 
Desain kedua APO tersebut merupakan pengembangan dari desain yang telah ada di lapangan, untuk desain APO ban bekas dasarnya mengadopsi dari APO yang dikembangkan Friend of The Earth (FoE) Jepang di Kecamatan Tugu. Sementara itu, APO HE mengadopsi desain Kementerian Kelautan dan Perikanan (KKP) yang dibangun di Kecamatan Genuk pada tahun 2016. Gambar 2 memperlihatkan APO ban di Karanganyar dan Tugurejo serta HE di Kecamatan Trimulyo.

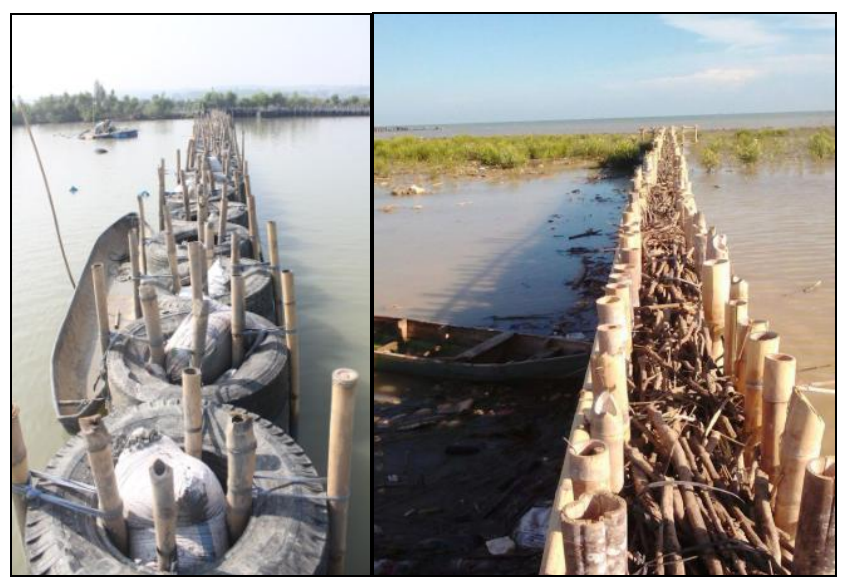

Sumber: Dokumentasi Penulis, 2016

Gambar 2. APO Ban di Karanganyar dan Tugurejo serta HE di Trimulyo

\section{Monitoring Pembangunan APO di Kecamatan Tugu}

Berdasarkan rencana workplan yang telah dibuat, seharusnya pembangunan APO dimulai pada pertengahan tahun 2014. Akan tetapi, pembangunan APO baru di mulai pada Maret 2015. Hal ini dikarenakan beberapa hal di antaranya kesalahan prediksi kondisi cuaca sehingga prediksi tinggi gelombang pun tidak tepat dan sulitnya mencari material bangunan. Selain itu, harga material juga mengalami kenaikan. Pemilihan lokasi untuk pembangunan APO didasarkan pada keberadaan tambak yang terkena risiko abrasi dan tambak-tambak yang berhadapan langsung dengan laut pantura. Kesediaan pemilik tambak menjadi titik kunci untuk memastikan pengembangan APO dapat melindungi tambak mereka. Pembangunan APO ini dilakukan oleh kelompok Prenjak dan Kelompok Sido Rukun. Kelompok Prenjak bertugas untuk menyiapkan material dan kelompok Sido Rukun bertindak sebagai pekerja dan penyedia lokasi tambak yang akan dibangun APO. Dilihat dari waktunya maka pembangunan APO di Karanganyar dan Tugurejo kurang lebih dilakukan selama 1 tahun 2 bulan, sedangkan 3 bulan pertama adalah tahap persiapan.

diharapkan dapat mencegah dan mengembalikan area yang terdampak abrasi. Konstruksi ini dikembangkan oleh Deltares dan pertama kali diterapkan di Pesisir Demak oleh Kementerian Kelautan dan Perikanan pada tahun 2013. 


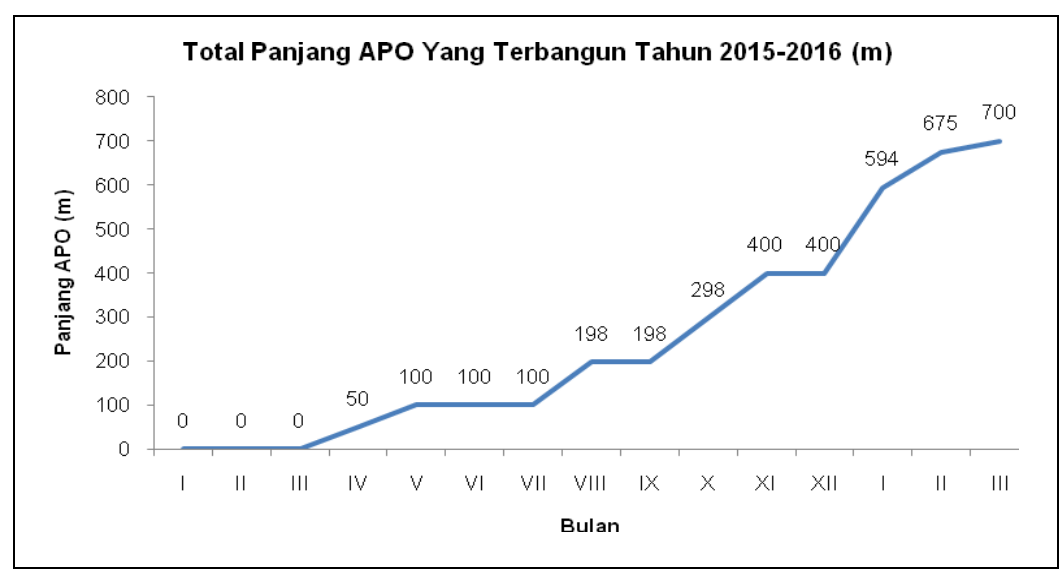

Sumber: Penyusun, 2016

\section{Gambar 3. Panjang APO yang Terbangun pada Tahun 2015-2016}

Gambar 3 menunjukkan panjang APO yang terbangun pada tahun 2015-2016. Panjang APO direncanakan 800 meter dan pada akhir 2015 panjang APO yang terbangun adalah 400 meter atau $50 \%$ dari target pembangunan. Pembangunan APO pada periode 1 dan periode 2 (198 meter atau 24,75\%) membutuhkan waktu enam bulan. Sementara itu, pada periode 3 dan periode 4 (202 meter 25,25\%) membutuhkan waktu tiga bulan. Pembangunan APO periode 5-7 dilanjutkan pada tahun 2016. APO sepanjang 300 meter tersebut diselesaikan dalam kurun waktu 3 bulan. Tabel 2 menunjukkan rincian per periode dan lokasi APO ban yang telah dibangun.

Tabel 2. Periode, Panjang dan Lokasi APO

\begin{tabular}{crll}
\hline Periode & Panjang (meter) & \multicolumn{1}{c}{ Lokasi } & Waktu Penyelesaian \\
\hline I & 100,00 & Tambak Pak Sugeng & 6 bulan \\
II & 98,00 & Tambak Pak Madyan & \\
\hline III & 100,00 & Tambak Pak Kaswan & 3 bulan \\
IV & 46,00 & Tambak Pak Juri & \\
& 56,00 & Tambak Pak Muhyi & 2 minggu \\
\hline V & 100,00 & Tambak Pak Muhyi & 2 minggu \\
\hline VI & 100,00 & Tambak Pak Muhyi & 2 minggu \\
\hline VII & 100,00 & Tambak Pak Muhyi (dari 100 m, 25 m & \\
& & merupakan inisiasi dari pemilik tambak & \\
& & sendiri) &
\end{tabular}

Sumber: Analisis Penulis, 2016

Pembangunan APO di periode 3 dan 4 lebih cepat dari sebelumnya disebabkan adanya perubahan pada pekerja. Pekerja sebelumnya kurang memiliki kecepatan dalam bekerja, sehingga pembagunan APO memerlukan waktu lebih lama. Perubahan pekerja sangat efektif karena pekerja yang baru lebih antusias dalam bekerja sehingga pekerjaan dapat diselesaikan lebih cepat. Kondisi tersebut mencerminkan kapasitas masyarakat sangat dibutuhkan untuk efisiensi kegiatan. Pentingnya pengalaman, pengetahuan, tipe 
kepribadian, latar belakang dan pemikiran sangat mempengaruhi tingkat pemberdayaan (Ahlstrom dalam Mattsson, Karlsson, Fast-Berglund, \& Hansson, 2014).

\section{Monitoring Pembangunan Hybrid Engineering (HE) di Kecamatan Genuk}

Pembangunan APO pada program yang diimplementasikan Mercy Corps Indonesia ditargetkan sepanjang 800 meter di Karanganyar dan Tugurejo. Akan tetapi, keterbatasan lokasi di Karanganyar dan Tugurejo membuat pembangunan hanya bisa dilakukan sepanjang 700 meter dan telah diselesaikan pada Maret 2016. Untuk memenuhi kekurangan APO yang belum terbangun sepanjang 100 meter, kemudian Trimulyo dipilih sebagai lokasi untuk melanjutkan pembangunan. Akan tetapi dengan adanya perbedaan karakteristik jenis substrat maka jenis APO yang dikembangkan berbeda, yaitu berupa Hybrid Engineering (HE) atau pemecah ombak bermaterial bambu. Berikut adalah kriteria pertimbangan pemilihan desain pemecah ombak di Trimulyo:

1) Berbeda dengan pantai berpasir yang ada di Karanganyar dan Tugurejo, pantai Trimulyo berlumpur dan memiliki lokasi yang langsung berbatasan dengan laut lepas sehingga jenis APO ban bekas dirasa kurang tepat dan kuat jika diterapkan di Trimulyo.

2) Fungsi dari APO ban bekas adalah untuk melindungi tambak sedangkan di Trimulyo jumlah tambak berbatasan dengan laut hampir tidak ada.

3) Fungsi pemecah ombak di Trimulyo lebih ditekankan pada penangkap sedimentasi karena tingginya erosi yang ada di Trimulyo dan abrasi yang menggerus daratan. Sedimen yang tertangkap diharapkan dapat menimbulkan daratan baru yang dapat digunakan untuk membudidayakan tanaman mangrove.

4) Menyesuaikan desain pemecah ombak yang ada sebelumnya, yakni pemecah ombak yang dibangun oleh Kementerian Kelautan dan Perikanan berupa pemecah ombak Hybrid Engineering (HE).

Panjang HE yang direncanakan dibangun di Trimulyo adalah 200 meter. Panjang ini merupakan konversi dari biaya yang dibutuhkan untuk membangun 100 meter APO ban sehingga target program justru terlampaui dengan adanya pembangunan $\mathrm{HE}$ ini. Pembangunan HE di Trimulyo dilakukan oleh Kelompok Sringin.

Pembagunan HE dimulai pada Februari 2016, yaitu dimulai dengan persiapan penyusunan KAK pembangunan $\mathrm{HE}$, penyiapan material dan penentuan lokasi yang tepat dengan masyarakat serta diskusi dengan masyarakat terkait KAK yang telah disusun. Pada bulan Maret, pembangunan telah mencapai 130 meter atau telah mencapai $65 \%$. Pada bulan April pembangunan telah mencapai 100\% atau 200 meter. Namun demikian, masih perlu penyelesaian pemberian ranting pada ruang tengah $\mathrm{HE}$ dan pengikatan bambu dengan ranting supaya HE lebih kuat. Pada awal Mei, HE sepanjang 200 meter sudah selesai dibangun di Trimulyo. Untuk itu, waktu yang perlukan secara keseluruhan adalah 2 bulan 1 minggu. Gambar 5 memperlihatkan total HE yang terbangun per bulan di Trimulyo.

Berdasarkan Gambar 5, dapat diketahui bahwa total panjang pemecah ombak yang terbangun adalah 900 meter, hal ini melebihi target awal yang panjangnya 800 meter. 900 meter tersebut terdiri atas 700 meter (78\%)APO ban bekas yang terletak di Karanganyar dan Tugurejo serta 200 meter (22\%) Hybrid Engineering (HE) yang terletak di Trimulyo. 


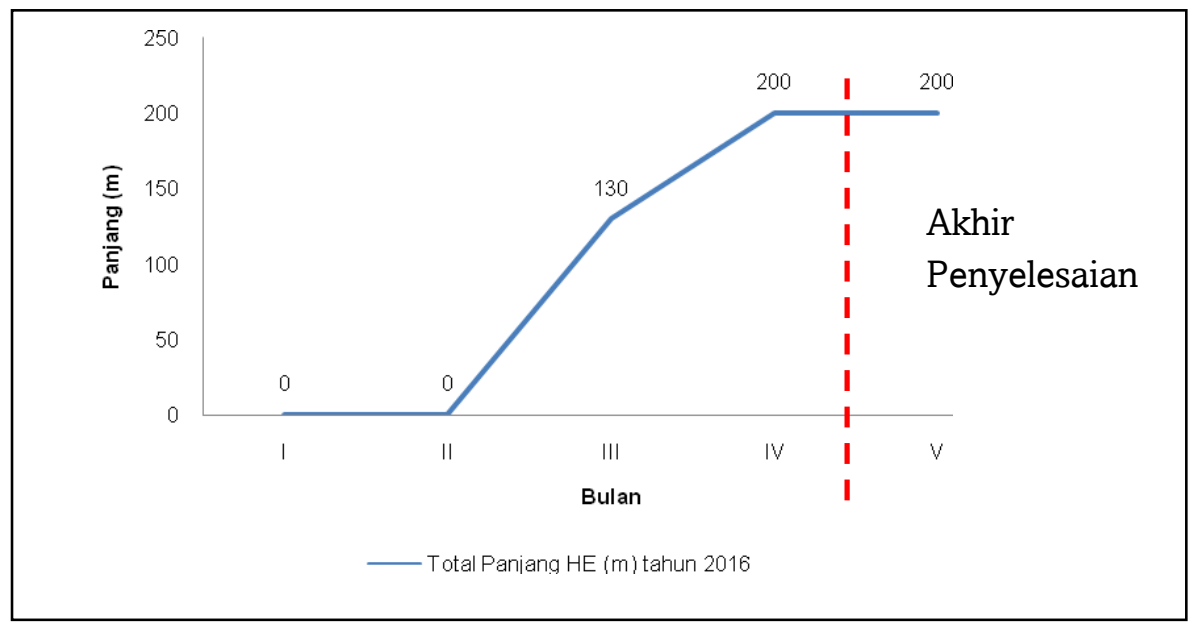

Sumber: Analisis Penulis, 2016

\section{Gambar 5. Total HE yang Terbangun Setiap Bulan}

\section{Peranan Masyarakat dan Manfaat Pembangunan APO}

Masyarakat yang terlibat dalam pembangunan pemecah ombak di Tugurejo berjumlah 5 orang, namun salah satunya telah meninggal dunia yaitu Bapak Madyan sehingga saat ini tambaknya dialihkan kepada Bapak Kaswan. Tabel 3 adalah daftar nama yang tambaknya dijadikan sebagai lokasi pembangunan APO (kecuali HE tidak dibangun diatas tambak).

\section{Tabel 3. Nama Penyedia Lokasi APO}

\begin{tabular}{clll}
\hline No & Nama & Kelompok & Jenis Pemecah Ombak \\
\hline $\mathbf{1}$ & Muhyi & Kelompok Tani Tambak Sido Rukun & APO ban \\
$\mathbf{2}$ & Kaswan & - & APO ban \\
$\mathbf{3}$ & Sugeng & Kelompok Tani Tambak Sido Rukun & APO ban \\
$\mathbf{4}$ & Juri & Kelompok Tani Tambak Sido Rukun & APO ban \\
$\mathbf{5}$ & Madyan & (Sudah meninggal dunia) & APO ban \\
$\mathbf{6}$ & Sumadi & Sringin & APO bambu (HE) \\
$\mathbf{7}$ & Yudi & Sringin & APO bambu (HE) \\
\hline \multicolumn{2}{l}{ Sumbe: Analisis } & Penulis, 2016 &
\end{tabular}

Dalam pembangunan APO ban, masyarakat memiliki peran yang berbeda-beda. Meskipun masyarakat menyediakan lokasi untuk pembangunan APO, namun tidak semua tambak yang dimiliki adalah milik mereka sendiri, dimana ada sebagian yang menyewa dan sebagian mengelola tanpa membayar uang sewa. Dalam pembangunan HE, masyarakat yang terlibat yaitu sebagai pekerja karena HE tidak dibangun diatas tambak. Dapat dilihat pada Gambar 4 bahwa sebanyak 2 orang (33\%) masyarakat berperan sebagai pemilik tambak, 2 orang (33\%) sebagai pekerja HE, 1 orang (17\%) sebagai pengelola tambak, dan 1 orang $(17 \%)$ sebagai penyewa tambak. Hal ini memperlihatkan bahwa secara umum persentase penyedia tambak yang digunakan untuk pembangunan APO tanpa melihat status kepemilikan tambak adalah sejumlah $66 \%$. Keterlibatan masyarakat tidak hanya pada awal kegiatan, seperti mengusulkan pekerja namun juga terlibat dalam pembangunan dan pengawasan APO. 


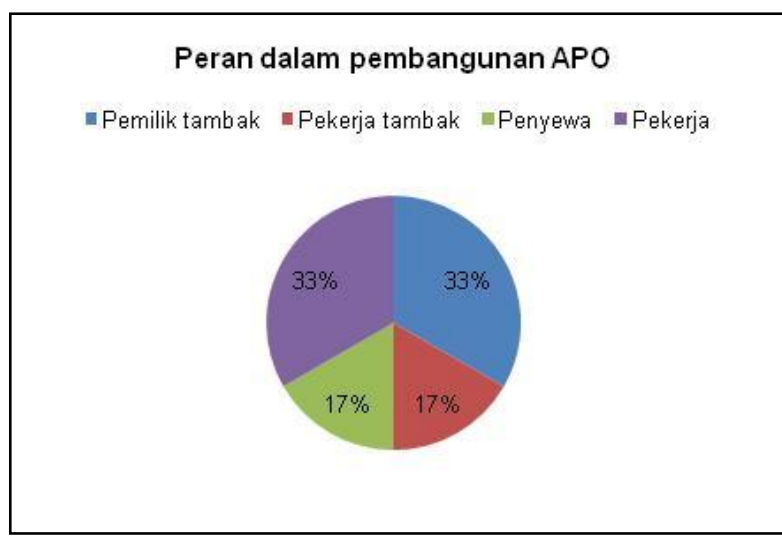

Sumber: Analisis Penulis, 2016

\section{Gambar 4. Peran dalam Pembangunan APO}

Partisipasi masyarakat juga dilihat dari swadaya yang pemberian berupa karung tanah untuk mengisi ruang tengah ban pada APO (lihat Gambar 5.).

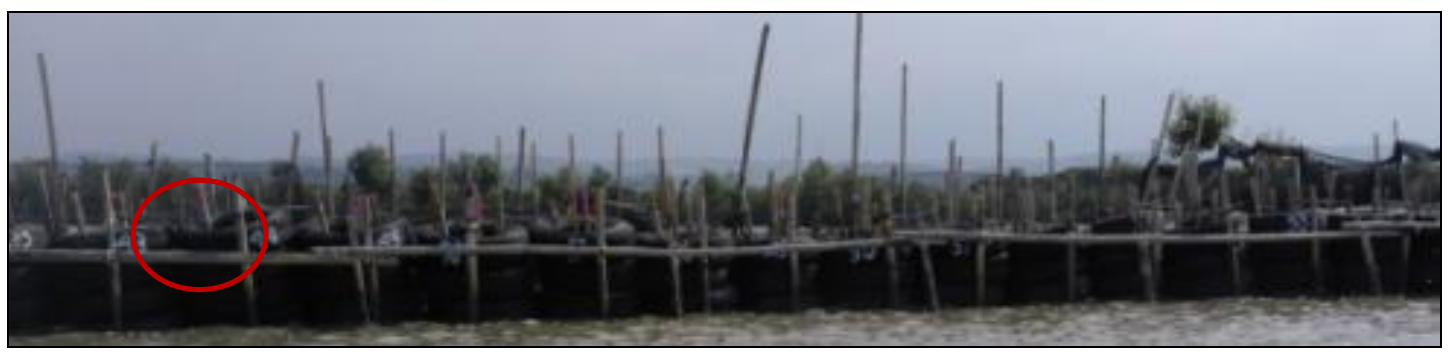

Sumber: Dokumentasi Penulis, 2015

\section{Gambar 5. APO Ban di Kecamatan Tugu}

Selain memberi tanah urug, masyarakat juga memberi nomor pada APO sehingga saat monitoring perhitungan lebih cepat dilakukan. Swadaya juga dilakukan secara sukarela oleh masyarakat yaitu 25 meter dari APO ban di Karanganyar dan Tugurejo merupakan inisiatif dari pemilik tambak.

Dalam keterlibatan pembangunan pemecah ombak ini masyarakat memiliki motivasi yang berbeda-beda. Berikut adalah motivasi yang menjadikan masyarakat mau terlibat dalam pembangunan APO:

- Masyarakat mau terlibat karena kecintaan mereka terhadap tambak. Masyarakat merasa tambak mereka dalam keadaan terancam sehingga demi keselamatan tambak mereka termotivasi untuk terlibat dalam pembangunan pemecah ombak.

- Untuk menanggulangi abrasi, agar tambak lebih tahan dari terjangan ombak.

- Untuk menyelamatkan lingkungan karena jika tidak ada APO, air laut bisa masuk ke kampung mereka.

- Masyarakat merasa APO memiliki manfaat, seperti melindungi tanaman dan mangrove yang ada di pesisir.

Keterlibatan dalam pembangunan APO pada program yang dikembangkan oleh Mercy Corps Indonesia ini bisa jadi bukan merupakan keterlibatan masyarakat yang 
pertama kalinya dalam pembangunan APO. Hal ini dikarenakan baik di Karanganyar, Tugurejo, dan Trimulyo telah ada pembangunan pemecah ombak sebelumnya. Sejumlah 83\% masyarakat telah terlibat dalam pembangunan pemecah ombak sebelumnya dan sejumlah $17 \%$ belum pernah terlibat dengan pembangunan pemecah ombak sebelumnya. Menurut penuturan masyarakat terdapat perbedaan dalam pembangunan pemecah ombak sebelumnya dengan pembangunan pemecah ombak dari Mercy Corps Indonesia (MCI). Perbedaan tersebut diantaranya adalah:

- Desain APO ban milik MCI lebih baik karena desain bisa dikembangkan dengan penambahan tanggul sehingga bisa menaikkan sedimen/endapan yang akhirnya menyebabkan tambak memiliki pematang.

- $\quad$ Pembangunan APO MCI juga dinilai tidak hanya menguntungkan untuk diri sendiri akan tetapi juga menguntungkan untuk orang lain karena pembangunan juga melibatkan masyarakat lain sebagai pekerja.

- Pembangunan APO MCI juga dinilai lebih kuat secara konstruksi karena pembangunan dilakukan oleh masyarakat bukan oleh pihak ketiga sehingga pemilihan material lebih baik.

- $\quad$ Pembangunan dilakukan langsung oleh masyarakat sehingga masyarakat tidak hanya dilibatkan sebagai pekerja akan tetapi juga berpartisipasi dalam pemilihan material yang lebih bagus. Partisipasi masyarakat dinilai lebih tinggi.

Pembangunan pemecah ombak oleh MCI ini oleh 100\% masyarakat dinilai membawa dampak positif, yaitu:

- Terlihat lebih aman dari terjangan ombak dan angin sehingga tambak menjadi lebih kuat.

- $\quad$ Tidak hanya tambak yang terlindungi, pematang tambak juga terlindungi.

- Tambak yang lebih kuat menghasilkan produksi ikan yang lebih besar saat panen karena APO dapat melindungi tambak dari abrasi yang menyebabkan tanggul atau pematang jebol sehingga ikan banyak yang keluar dari tambak.

- Tambak yang aman dan kuat juga mengurangi pengeluaran petani untuk perawatan tambak seperti untuk perbaikan tanggul dan sebagainya.

- Mencegah terjadinya abrasi.

- Menambah sedimentasi (tanah) sehingga tanaman mangrove terlindungi.

- Pembangunan HE mampu melindungi tanaman mangrove yang ada di belakangnya.

Selain dampak positif yang dirasakan masyarakat, seperti tambak yang lebih terlindungi, masyarakat juga merasakan adanya hal positif yang didapat dari keterlibatan mereka dalam proses pembangunan pemecah ombak. Dampak positif yang dirasakan adalah meningkatnya keterampilan dan pengetahuan mereka dalam menangani dampak negatif yang dibawa oleh gelombang air laut yang tinggi, yaitu dengan membangun pemecah ombak yang harganya tidak terlalu mahal (HE tergolong murah dibandingkan dengan jenis pemecah ombak lainnya). Masyarakat juga memahami bahwa lokasi pembangunan sangat penting dipertimbangkan karena semahal apapun alat yang dibangun jika lokasi pembangunan tidak tepat pasti bisa hancur. Akan tetapi, bangunan yang murah dapat kuat terjaga karena lokasi pembangunan dipilih secara tepat.

Besarnya dampak positif yang dirasakan oleh masyarakat menjadikan mereka sadar untuk terus melakukan upaya perawatan. Sejumlah $83 \%$ masyarakat mengaku berkeinginan untuk terus melakukan perawatan APO secara mandiri. Hanya ada 17\% masyarakat yang tidak bisa melakukan perawatan secara mandiri dikarenakan sudah tua dan akan meminta tolong pada orang lain melakukan perawatan. Upaya perawatan yang dilakukan antara lain:

- Memberi tanah sedimen dan pasir yang dimasukkan dalam karung serta ranting dalam ruang kosong ditengah ban sehingga APO tidak goyah ketika terkena gelombang dan masyarakat dapat menanam mangrove di atasnya.

- $\quad$ Memberikan waring pada sekeliling APO ban agar dapat menangkap sedimentasi. 
- Mengganti bambu yang sudah lapuk/ rusak dan melilitnya dengan kain limbah sehingga dapat bertahan hingga sekitar 3 tahun. Disamping itu menambah sedimen di belakang APO agar keberadaan APO tersebut bisa stabil.

- $\quad$ Pada HE masyarakat melakukan jadwal kontrol secara rutin untuk mengontrol bambu karena tak jarang HE digunakan sebagai tempat istirahat oleh pencari ikan.

- $\quad$ Kontrol mengelilingi APO dengan melihat apakah terdapat kerusakan atau tidak.

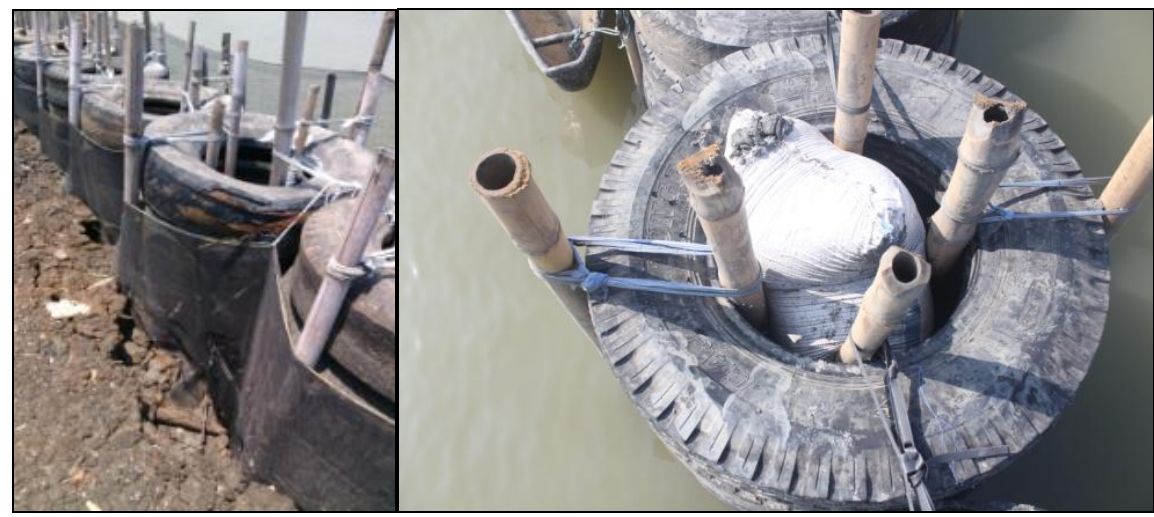

Sumber: Dokumentasi Penulis, 2015-2016

\section{Gambar 5. Pemberian Waring di Sekeliling APO dan Pemberian Karung Berisi Tanah di Dalam Ban}

Dari penjelasan diatas maka dapat disimpulkan bahwa pembangunan APO baik di Karanganyar, Tugurejo dan Trimulyo secara umum membawa dampak positif bagi masyarakat. Banyaknya dampak positif yang dirasakan masyarakat ini juga yang menyebabkan masyarakat menjadi sadar untuk terus merawat pemecah ombak yang telah dibangun sehingga dampak positif ini dapat mereka rasakan dalam jangka waktu yang lama.

\section{Pembelajaran (Lesson Learned) dari Pembangunan APO oleh Mercy Corps Indonesia}

Kegiatan pembangunan pemecah ombak oleh MCI ini tentu memberikan pembelajaran yang dapat dijadikan masukan pada kegiatan yang sama yang akan dilakukan dimasa yang akan datang sehingga tujuan dapat tercapai secara lebih baik lagi. Beberapa pembelajaran yang didapat antara lain:

- $\quad$ Secara finansial, HE lebih membutuhkan biaya yang lebih sedikit dibandingkan APO. Namun, pembangunan keduanya dibangun pada kondisi pesisir yang berbeda. APO ban untuk jenis pesisir yang berpasir sedangkan HE untuk jenis pesisir tanah liat.

- $\quad$ Dampak positif yang dirasakan dapat meningkatkan kesadaran yang tinggi untuk masyarakat. Dengan demikian, maka di awal kegiatan dapat disampaikan pemahaman kepada masyarakat terkait manfaat kegiatan. Hal ini dapat dilakukan melalui best practice di tempat lain yang telah melakukan kegiatan yang sama. Kegiatan ini dapat memberi motivasi masyarakat untuk terlibat dan kemudian melakukan perawatan terhadap bangunan yang mereka bangun menjadi lebih tinggi.

- Ketepatan memilih pekerja untuk membangun APO. Pekerja yang tidak antusias dan memiliki integritas dalam melakukan pembangunan dapat diberi punishment dengan cara penggantian pekerja. Selain punishment, reward juga dapat diberikan kepada 
pekerja agar motivasi masyarakat semakin tinggi. Reward ini juga memiliki andil untuk meningkatkan performa seperti yang diungkapkan oleh Mattsson et al. (2014)

- $\quad$ Pentingnya koordinasi dengan kelompok masyarakat yang peduli lingkungan pesisir di wilayah tersebut untuk memberikan informasi terkait pemilihan pekerja.

- $\quad$ Upaya perawatan yang dilakukan oleh masyarakat dapat pula dijadikan sebagai masukan dalam Buku Pedoman Pembangunan APO pada bagian Hal-hal Paska Pembangunan APO.

- Perlunya koordinasi dengan dinas atau instansi lain yang berwenang dalam pembangunan APO. Hal ini untuk menghindari kesalahan penempatan lokasi pemecah ombak.

- $\quad$ Pemberian nomor pada ban memberikan kemudahan dalam pelaksanaan monitoring.

- Kesediaan pemilik tambak menjadi salah satu kunci keberhasilan dalam pembangunan APO ban.

- $\quad$ Pentingnya swadaya dari masyrakat sehingga tidak hanya mengandalkan bantuan.

\section{Kendala Selama Pembangunan APO}

Adapun yang menjadi kendala dalam pembangunan APO adalah:

- Hujan, ombak, air pasang dan angin besar menyebabkan pekerjaan tidak maksimal. Ombak juga merusak pinggiran bangunan APO.

- Pasang surut pada siang hari menyebabkan pengangkutan material sulit dilakukan. Sementara itu, jika dilakukan pada malam hari lebih berisiko karena pandangan tidak terlalu jelas.

- Kenaikan harga dan kesulitan mendapatkan material.

- Keterbatasan waktu untuk perawatan APO.

- Kurang tersalurkannya dengan baik distribusi bantuan.

- Kurangnya tenaga kerja.

- Keterbatasan material berupa ban.

- Banjir menyebabkan kesulitan membawa ranting pengisi HE.

- Perbedaan persepsi antara masyarakat dengan implementer kegiatan. Masyarakat menganggap APO mempersempit luasan tambak mereka.

- Tinggi APO yang dirancang tidak sesuai dengan kedalaman air laut sehingga ban yang dibutuhkan menjadi lebih banyak

\section{Kesimpulan dan Rekomendasi}

Pembangunan APO baik di Karanganyar, Tugurejo maupun Trimulyo sudah melampaui target pembangunan 800 meter pemecah ombak karena total yang terbangun adalah 900 meter yang terdiri dari 700 meter (78\%) APO ban dan 200 meter (22\%) Hybrid Engineering (HE). Total waktu yang diperlukan untuk membangun seluruh pemecah ombak adalah 1 tahun 2 bulan. Pembangunan APO memberikan dampak positif bagi masyarakat sehingga masyarakat secara sadar melakukan perawatan secara mandiri agar dampak positif yang mereka terima dapat mereka rasakan hingga jangka waktu yang lama. Dampak tersebut dirasakan oleh masyarakat yang terlibat secara langsung maupun masyarakat secara luas. Manfaat dirasakan pada aspek ekonomi dan lingkungan. Manfaat paling besar bagi masyarakat adalah meningkatnya penghasilan karena tambak terlindungi dan tanah sedimentasi yang terbentuk menyediakan tempat untuk mencari ikan dan kepiting lebih luas. Informasi iklim menjadi salah satu aspek penting yang dibutuhkan dalam proses pengerjaan pemecah ombak karena kendala pengerjaan pemecah ombak 


\section{Penguatan Ekosistem Pesisir: Monitoring dan Pembelajaran Pembangunan Alat Pemecah Ombak (APO)...}

utamanya ada pada kondisi cuaca yang tidak bisa diprediksi. Hal yang perlu ditingkatkan dari kegiatan pembangunan APO selanjutnya antara lain:

- Adanya inovasi baru dalam pembangunan APO.

- $\quad$ Meningkatkan kerjasama antar kelompok.

- $\quad$ Pada HE perlu diangun APO ban di belakang pasir untuk melindungi tanaman dari air pasang.

- Pelibatan pemuda dalam pembangunan.

- Penyediaan informasi iklim guna memberikan perkiraan waktu yang tepat dalam pembangunan APO.

- $\quad$ Penggunaan bambu dan jaring untuk meningkatkan penanggulangan abrasi oleh APO. Bambu juga diperlukan untuk mengganti bambu yang telah lapuk dan rusak.

- $\quad$ Peningkatan tenaga kerja dan modal.

- $\quad$ Peningkatan penanggulangan abrasi, seperti penyediaan bambu untuk mengganti bambu yang telah lapuk.

\section{Daftar Pustaka}

Al Hakim, B., Wibowo, M., Kongko, W., Irfani, M., Hendriyono, W., \& Gumbira, G. (2015). Hydrodynamics modeling of giant seawall in Semarang Bay. Procedia Earth and Planetary Science, 14, 200 - 207. doi:10.1016/j.proeps.2015.07.102

Astra, A. S., Etwin K. S., Arief M. H., \& Maulana, M. B. (2014). Keterlibatan masyarakat dalam pengelolaan pesisir dan laut. Studi kasus: Kawasan perlindungan pesisir Desa Timbulsloko, Kecamatan Sayung, Kabupaten Demak. Bogor: Wetlands International Indonesia.

Badan Pusat Statistik (BPS) Kota Semarang. (2010). Kota Semarang dalam angka tahun 2010. Kota Semarang: BPS Kota Semarang.

Dunn, W. N. (2002). Pengantar analisis kebijakan publik. Yogyakarta: Gadjah Mada University Press.

Hartati, R., Pribadi, R., Astuti, R. W., Yesiana, R., \& Yuni, I. (2016). Kajian pengamanan dan perlindungan pantai di wilayah pesisir Kecamatan Tugu dan Genuk, Kota Semarang. Jurnal Kelautan Tropis, 19 (2), 95-100.

Huang, M., \& Liu, J. (2009). Monitoring and analysis of Shanghai Pudong seawall performance. Journal of Performance of Constructed Facilities, 23, 399-405. doi:10.1061/_ASCE_CF.1943-5509.0000057.

Kusmana, C. (2010). Respon mangrove terhadap pencemaran. Bogor: IPB.

Mattsson, S., Karlsson, M., Fast-Berglund, A., \& Hansson, I. (2014). Managing production complexity by empowering workers: Six cases. Procesia CIRP, 17, 212-217. doi:10.1016/j.procir.2014.02.041.

Suhelmi, I. R., \& Prihatno, H. (2014). Model spasial dinamik genangan akibat kenaikan muka air laut di Pesisir Semarang. Jurnal Manusia dan Lingkungan, 21(1), 15-20. doi:10.22146/jml.26.

Susandi, A., Herlianti, I., Tamamadin, M., \& Nurlela, I. (2008). Dampak perubahan iklim terhadap ketinggian muka laut di wilayah Banjarmasin. Jurnal Ekonomi Lingkungan, 12(2), 1-8.

Triatmodjo, B. (1999). Teknik pantai. Yogyakarta: Beta Offset.

Wahyudi, F. (2016). Pengertian pemecah ombak (breakwater) [Web log PT. Anugerah Atlantik]. Retrieved from http://www.kubusapung.id/post/8/pengertian-pemecah-ombak-breakwater.html.

Wiharja, P., \& Nafiarta, H. N. A. (2015). "Hybrid Engineering” sebagai solusi perlindungan pantai dan awal penanaman kembali hutan mangrove [Online article from Pusat Pendidikan dan Pelatihan Sumberdaya Manusia, Lingkungan Hidup, dan Kehutanan, Kementerian Lingkungan Hidup dan Kehutanan]. Retrieved from http://bp2sdmk.dephut.go.id/pusdiklat/?p=963.

Yulistiyanto, B. (2009). Mangrove dengan Alat Pemecah Ombak (APO) sebagai perlindungan garis pantai. Paper presented at Seminar Nasional Manajemen Sumberdaya Air Partisipatif Guna Mengantisipasi Dampak Perubahan Iklim Global, Universitas Islam Indonesia, Yogyakarta. 